\title{
PRIMARY AND SECONDARY POWER CONTROL OF MULTITERMINAL HVDC GRIDS
}

\author{
A. Egea-Alvarez ${ }^{*}$, J. Beerten ${ }^{\dagger}$, D. Van Hertem ${ }^{\dagger}$, O. Gomis-Bellmunt* \\ * CITCEA-UPC, Departament d'Enginyeria Elèctrica, Universitat Politècnica de Catalunya. Barcelona, Spain \\ $\dagger$ ELECTA, Electrical Engineering Department, KU Leuven, Leuven, Belgium \\ contact: agusti.egea@citcea.upc.edu, jef.beertendesat.kuleuven.be, \\ dirk.vanhertem@esat.kuleuven.be, gomis@citcea.upc.edu
}

Keywords: Multiterminal High voltage direct current (MHVDC), Offshore wind power, Power flow control, primary and Secondary control, Hierarchical control.

\section{Abstract}

The article introduces a hierarchical control structure for Multiterminal High Voltage Direct Current (M-HVDC) systems. The presented hierarchy is similar to the control structure of the classical AC systems divided in primary, secondary and tertiary control. The design and interaction between the secondary, or power control, and the primary controllers, or voltage control, are discussed. Furthermore, the operation characteristics and operation points are commented. Some scenarios have been simulated in order to test and verify the proposed method including a power reference change and a grid side converter disconnection.

\section{Introduction}

There is a growing interest in the installation and development of offshore wind farms. In 2011 in Europe, 866 MW of offshore wind power have been installed. It represents around of the $10 \%$ of the new wind power installed in Europe [1]. Nowadays, the dominant transmission technology is the classical HVAC (High Voltage Alternating Current) but some offshore wind farm transmissions cables using an HVDC (High Voltage Direct Current) system have been built and now are planned [2]. The choice between different transmissions technologies is a technical-economical problem [3,4].

A step further is the creation of a DC grid [5]. There are several projects and initiatives focus on the development of a M-HVDC (Multiterminal-HVDC) grid. Examples of that are the European supergrid or the DESERTEC projects $[6,7]$. The main concept of both projects is to create a pan-European system to integrate a large amount of renewable energy resources to the AC grid. A supergrid intends to integrate all electrical generation in Europe into the grid and the DESERTEC initiative aims to integrate the power generated in large solar power plants in the North of Africa.

VSC-HVDC (Voltage Source Converter) is the most likely technology use for M-HVDC systems. Compared to LCC-HVDC (Line Commuted Converter), VSC-HVDC power converters permit independent control of active and reactive power [8] and easier control [9]. Furthermore, VSC technology permits to create a voltage after a blackout [10].

There are several challenges to be addressed in the development of the M-HVDC grids. Protection and control is one of the biggest issues to be solved. The operation of reliable DC grid requires DC breakers [11]. These breakers are not yet available commercially, but prototypes are presented [12].

The voltage control maintain the voltage stability. For Back-toBack HVDC systems, the voltage is controlled using an unique local control that maintain constant ot [13]. For M-HVDC applications other controllers and controllers coordination are used [14], but the most studied controller is the droop controller. The droop controller is a robust DC voltage controller that permits power sharing between different power converters [15]. Some authors have studied the dynamic behaviour of the MHVDC system controlled by means of a droop controller [16]. Also some advanced droop design methodologies have been proposed [17].

From the point of view of the power flow control, the use of the droop control does not permit to fix the power that is injected by a power converter. For this reason, a new control loop must be added. Some authors propose a centralized controls that give an optimized voltage reference to the local controllers [18] using a fast communications system. Others propose to design the power controller regarding the power flow control in the steady state. [19].

In this article a hierarchical control structure for M-HVDC systems is presented. First the droop voltage control, or primary control, is commented. In the next step, the power or secondary control, is introduced and discussed. Furthermore, the operating point and areas of the M-HVDC are described. The tertiary control is not in the scope of the present work. Finally, some scenarios have been simulated.

\section{Control structure description}

The proposed control scheme adds an upper level controller to the HVDC voltage control. The resulting control structure can be compared to classical AC grid controls, which are organized as primary, secondary and tertiary controls [20]. This structure permits to create an easy interaction between power dispatch and the lower controllers.

The voltage control corresponds to the AC primary control and aims to regulate the DC voltage within certain bounds. The voltage controller is implemented in each VSC power converter. Secondary control, or power control, is implemented to correct the exchanges so that the pre-fault conditions are restored. The practical implementation is a change of setpoints in the affected VSC controllers. The new setpoint is provided by a system-wide reference calculator. Finally a tertiary control mechanism calcu- 
lates the power reference according a more optimal operation power system: market, losses, security,... Tertiary control can be based on OPF (Optimal Power Flow) algorithms considering $\mathrm{AC}$ and DC grids. The internal current control loop of the power converters has the same function as the governor and the excitation of a synchronous generators. Figure 1 shows a comparison between the AC and the proposed DC control approach.

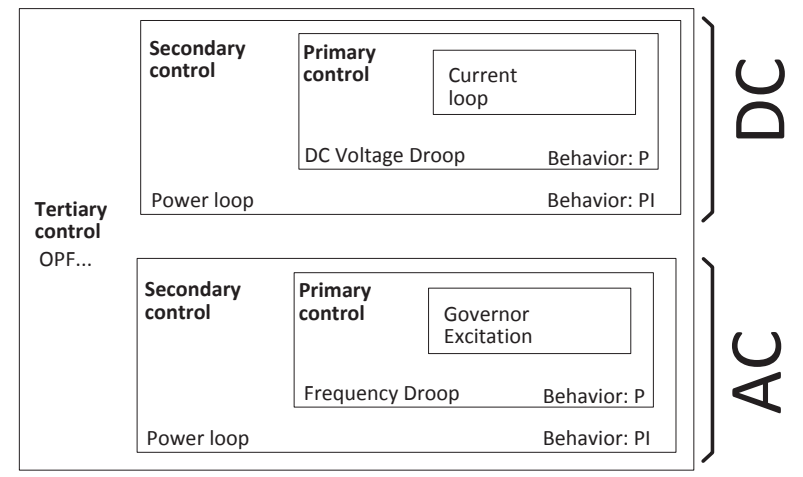

Figure 1: Comparison between AC and the proposed DC control approach

Although the control approach is quite similar, the respective time constants are not. The time constant for primary control loop is in the order of a few ms. For the secondary control it is some seconds. Traditional tertiary controllers are off-line algorithms that react between 20 minutes and 1 hour.

\subsection{Primary control}

The primary control or voltage control is the controller in charge of the DC voltage. The most common voltage control is the so called droop. It is a proportional control law that controls the DC current according to the DC voltage. The droop implementation for a rectifier and an inverter converter are defined in equation 1 and 2 respectively.

$$
\begin{aligned}
& I_{D C-r e c}^{*}=k_{\text {droop }}\left(E_{r e c}^{*}-E_{D C}\right) \\
& I_{D C-i n v}^{*}=k_{\text {droop }}\left(E_{D C}-E_{\text {inv }}^{*}\right)
\end{aligned}
$$

where $I_{D C}$ is the reference current, $k_{\text {droop }}$ is the gain of the droop controller, $E_{i n v}^{*}$ is the voltage offset for the inverter units and $E_{r e c}^{*}$ is the voltage offset of the rectifier units.

Figure 2 shows the operation characteristic of the droop controller under inverter operation (a), and rectifier operation (b). Once the power converter current limit is reached the current is saturated and no more power can be injected to the grid. The $k_{d r o o p}$ gain can be calculated following the methodology presented in [17].

Wind farms connected to the DC grid must inject all the generated power in the DC grid. When an electrical fault occurs, it may result in the saturation of power converter current limit and not all the power can be injected in the grid. As such, the DC voltage will rise quickly. In order not to exceed the maximum permitted voltage, a wind farm power reduction method is needed. The used power reduction method uses a droop characteristic that reduces the extracted power. This power reduction can be physically implemented using a DC chopper or a wind turbine reference change [21]. The power reduction control law is defined in equation 3 .

$$
P_{\text {wind }}^{r e d}=P_{\text {wind }}\left(1-k_{r}\left(E_{D C}-E_{1}\right)\right)
$$

where $P_{\text {wind }}$ is the wind farm power, $P_{\text {wind }}^{r e d}$ is the reduced wind farm power, $E_{D C}$ is the DC voltage and $k_{r}$ can be chosen as 4 .

$$
k_{r}=\frac{1}{E_{2}-E_{1}}
$$

where $E_{2}$ and $E_{1}$ are the upper and the lower thresholds of the $\mathrm{DC}$ voltage in terminals of the wind farm power converter.

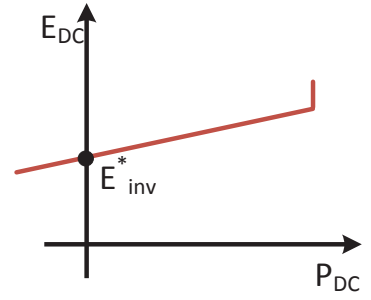

a)

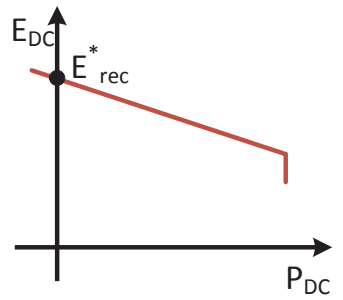

b)
Figure 2: Droop characteristics depending on the operation of the system

\subsection{Secondary control}

The secondary or power control can be described as a system that permits to achieve the power setpoints provided by a tertiary control. Furthermore, secondary control pretends to correct the power references after a contingency. In steady state, the main objectives of the secondary control are ensuring the power references and the power exchanges between the areas. A conceptual scheme of the proposed system can be seen in Figure 3.

The secondary controller is the link between the tertiary and de primary control. The power controller is divided in two parts. The first one is located in the power converter and aims to achieve the given power references modifying the droop gain. The second one is located remotely and performs the calculation that permit to recalculate new power references in case of change of the operational point.

\subsubsection{Local control structure}

The local power control is based on a PI controller that trades to achieve the desired power references without steady state error. The power controller regulates the power through the power converter modifying the reference of the droop controller. The droop offset, as the output of the power controller, is saturated in order not to exceed limits.

The power controller can be defined as $E^{*} / \Delta P=K_{p}+K_{i} / s$, where $K_{p}$ is the proportional gain of the controller and $K_{i}$ is the 


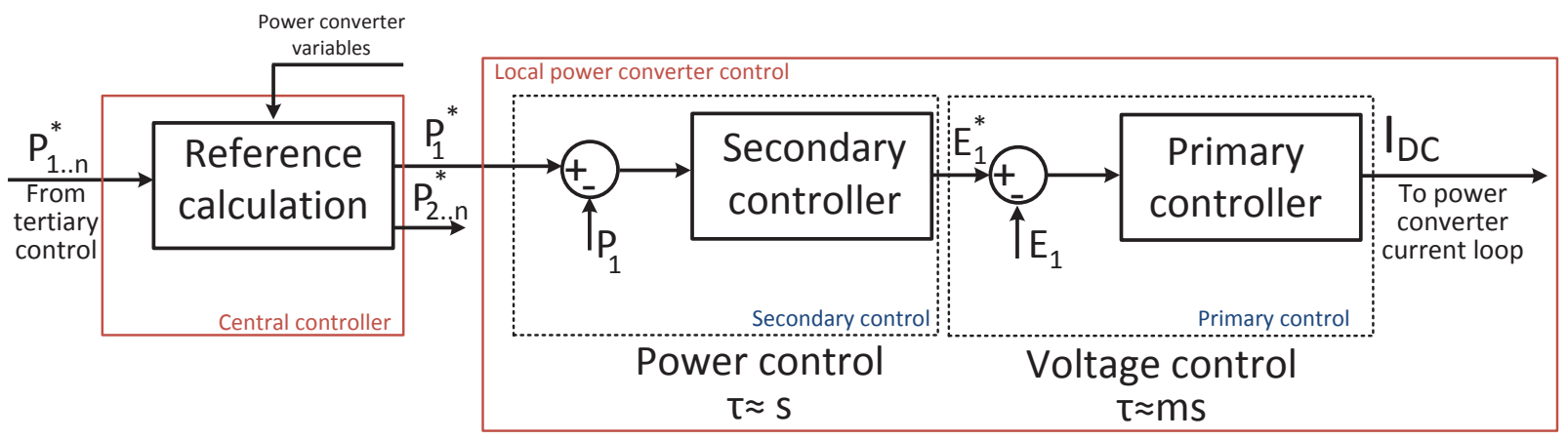

Figure 3: General scheme of the proposed control methodology

integral gain of the controller. The controller should be tuned to obtain a time response in the order of seconds.

\subsubsection{Central reference calculation}

The central reference recalculates the power references in case of a contingency or a deviation of the power references. The central reference calculation consists of a centralized controller that receives status information from the power converters, as well as, the power references given by the tertiary control. Its outputs are the sent new power references.

In normal operation, the sent power references match those given by the tertiary control and no reference modifications are required. In case of a power converter disconnection, the given references cannot be maintained. In this case, the central calculation tries to restore the power exchange between areas. This means that if an area is fed in by two power converters and one power converter is disconnected, the remaining power converter will inject the scheduled between areas or as much as possible power if the limits are reached (Figure 4).

The operation of the mentioned central calculation structure requires a communication system between the local power converter and the central calculation itself. Compared to other systems [18], the described system does not require a critical communication system due to the intrinsic safe operation characteristic of the proposed method.

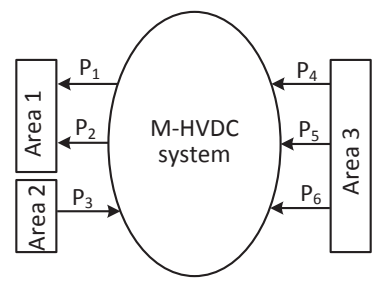

a)

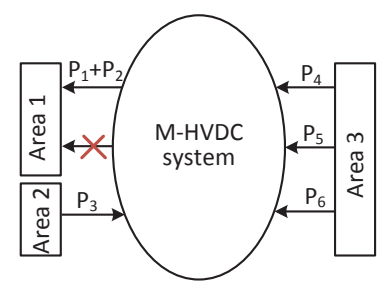

b)
Figure 4: Example of power balancing developed by the reference calculation

\subsubsection{Operating points}

During normal operation, the power controllers modify the reference of the droop controller to achieve the desired power flow through the power converter. As the power flow is a result of the difference between the DC voltages, more than one voltage configuration can produce the same power flow. For this reason, the voltage can oscillate between the given ranges in the constant power operation area. Figure 5 shows the characteristic behaviour for an inverter and a rectifier.

When the system operates in a faulted degraded state, as an AC voltage sag or a power converter disconnection, the power balancing in the system cannot be accomplished. In these cases, the operation of the system moves from the constant power area to the fixed droop area, where the voltage droop gain is saturated. The droop operation area is limited in the upper part by the $E_{\max -i}$ and $E_{\max -r}$ and the lower part by the $E_{\text {min }-i}$ and $E_{\min -r}$. The subscript $i$ refers to inverter and $r$ to rectifier. The appropriate selection of the described limits permits to operate the system under fault operation without exceeding the voltage limits while operating the system as an usual M-HVDC droop controlled system.

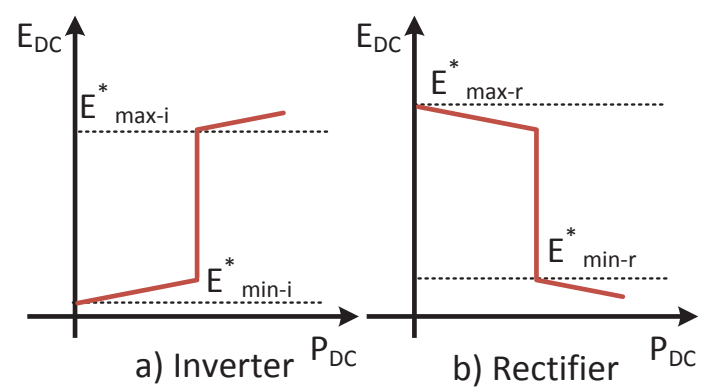

Figure 5: DC characteristic operation of the power converters for the proposed control methodology 


\subsection{Tertiary control}

The tertiary control is the upper control level and schedules the injections according to a given objective function taking economics and technical aspects into account, as well as their constraints. The tertiary control can be based on OPF algorithms. The required tertiary control used in the presented scheme can be a classical tertiary control considering DC transmission systems [22]. Losses can be considered in this stage of the system.

\section{Simulation}

Some scenarios have been simulated with Matlab-Simulink in order to test and verify the proposed control scheme. The first simulated scenario is a change in the power reference and the second scenario is a grid side converter disconnection.

The analysed system is composed by a four node M-HVDC system. One power converter is connected to a wind farm (WFC1), another power converter is connected to an AC grid (GSC3) and the two power converter are connected to a second AC grid (GSC1 and GSC2), considering an electrical distance between them in the grid side, represented as an AC line. In the studied case, the AC grids are modelled as Thevenin equivalent nodes. A sketch of the system can be seen in figure 6 .

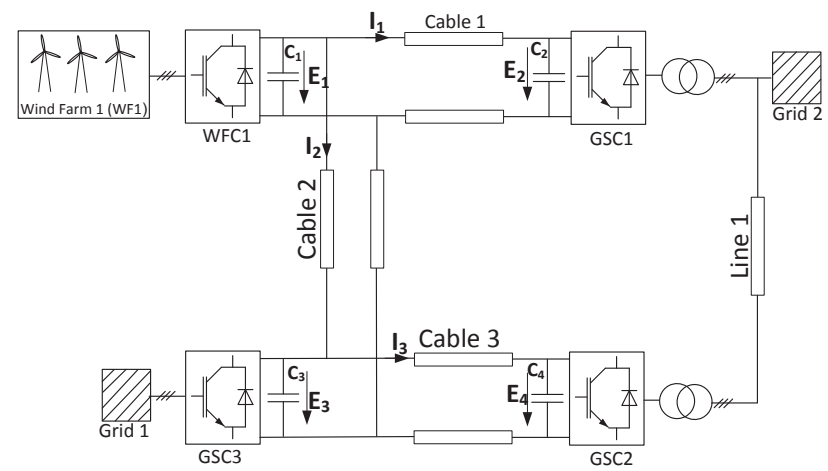

Figure 6: General scheme of the simulated multiterminal system

From the operation point of view, GSC1 and GSC2 are connected to the same grid working as an area operation. The sampling time of the communication system is 30s. This time can be lower but has been selected in order to demonstrate the viability of the system operation in a degraded scenario.

The used parameters are: $R_{\text {cable }}=0.01 \Omega / \mathrm{km}, \quad L_{\text {cable }}=0.1$ $\mathrm{mH} / \mathrm{km}, \mathrm{C}=150 \mu \mathrm{F}$, power converter nominal power of 100 MW. A droop gain of $1 / 10 \mathrm{kA} / \mathrm{kV}$. Cable 1 has a length of 100 $\mathrm{km}$, cable 2 of $20 \mathrm{~km}$ and cable 3 of $90 \mathrm{~km}$. The short-circuit power for grid 1 is $800 \mathrm{MW}$ and $400 \mathrm{MW}$ for grid 2. The thresholds for the secondary control saturation are $E_{\max -r}=165 \mathrm{kV}$ and $E_{\max -i}=152.4 \mathrm{kV}$ and the thresholds for the wind farm operation are $E_{1}=159 \mathrm{kV}$ and $E_{2}=165 \mathrm{kV}$. The parametres have been inspired from [23].

\subsection{Change of reference}

In the first scenario, a power reference change is simulated. At time instant $10 \mathrm{~s}$, a new power reference is sent to two grid side converters. The power changes are described in the table 1 . Figure 7 and figure 8 show the voltage and the power. Real values are expressed in continuous line and references values in dashed line.

In the initial time instant $0 \mathrm{~s}$, the system follows the references shown in Table 1. The real power is equal to the reference power and an equilibrium voltage points is reached. At time instant $10 \mathrm{~s}$, new power reference are sent to the GSC1 (inverter) and GSC3 (rectifier). As it can be seen in Figure 8 the power transmitted by the grid is increased by $20 \mathrm{MW}$. The dynamics of the system show the typical first order response with one second time constant.

From Figure 7, it can be seen that the voltages before and after the power reference change are quite similar. The biggest change can be observed in the voltage gain of the primary controller as a result of the secondary control in order to achieve the new voltage references.

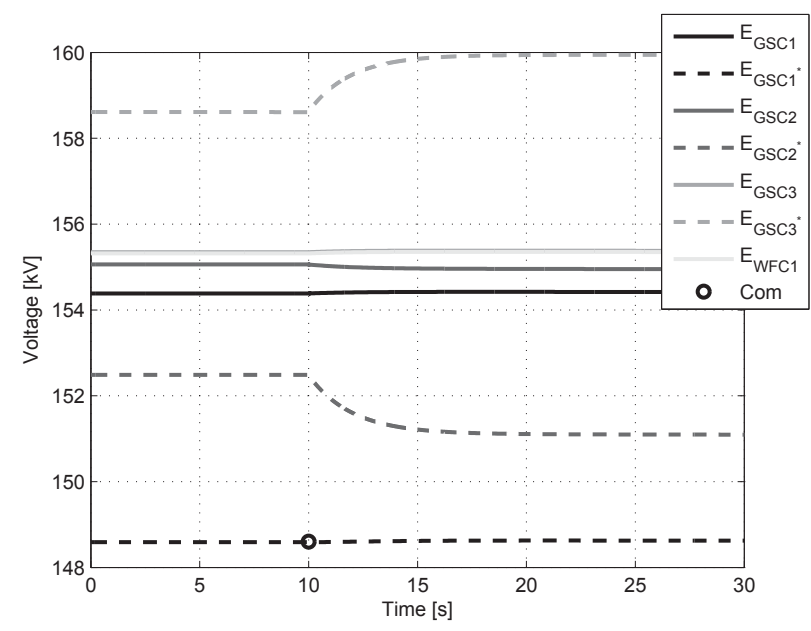

Figure 7: Voltage evolution during a reference change

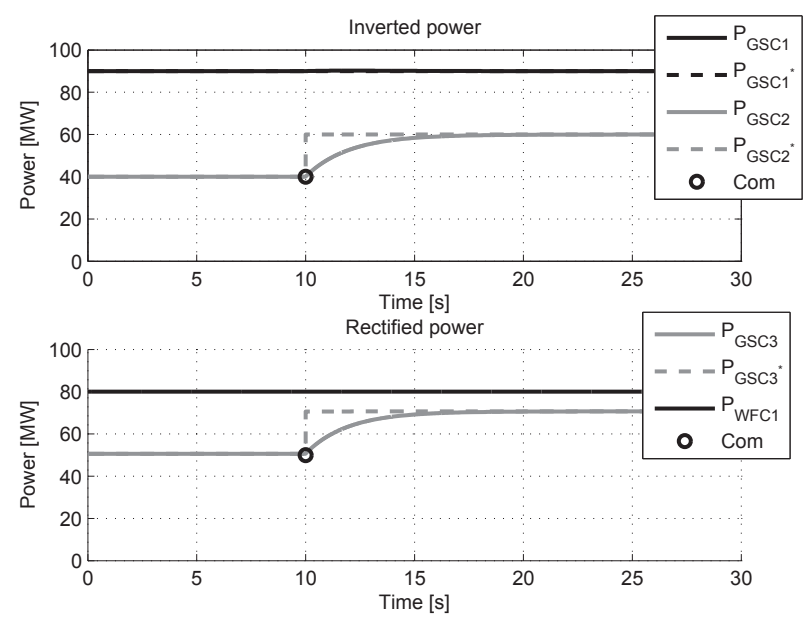

Figure 8: Power evolution during a reference change 


\begin{tabular}{l|c|c|l} 
Converter & Initial power & Final power & Behaviour \\
\hline GSC1 & $90 \mathrm{MW}$ & $90 \mathrm{MW}$ & Inverter \\
GSC2 & $40 \mathrm{MW}$ & $40 \mathrm{MW}$ & Inverter \\
GSC3 & $50 \mathrm{MW}$ & $70 \mathrm{MW}$ & Rectifier \\
WFC1 & $80 \mathrm{MW}$ & $80 \mathrm{MW}$ & Rectifier
\end{tabular}

Table 1: Initial and final power for the Change of reference scenario

\subsection{Power Converter disconnection}

In the second scenario, a power converter is disconnected. Figures 9 and 10 show the voltage and the power in the M-HVDC grid. At time instant 10s, a grid side power converter (GSC1) is disconnected. In this case the variable state of the system has been sent during the previous instants of the power converter disconnection.

During the first time instants, the power converter GSC1 was inverting $75 \mathrm{MW}$, the GSC2 was inverting $15 \mathrm{MW}$, the GSC3 was rectifying $60 \mathrm{MW}$ and the wind was generating $30 \mathrm{MW}$. At time instant 10s, GSC1 is disconnected and the HVDC system power balance is not in equilibrium. During the first milliseconds the droop action corrects the voltage deviation and immediately GSC3 reduces the rectified power and GSC2 increases the inverted power. After that, as the given power references are not readdressed, the secondary controllers starts to move the system droop gains. Between 10 s and $12 \mathrm{~s}$, the secondary controllers of all the power converters start to change the droop gains. At time instant 12s, GSC2's secondary control is saturated at the maximum limit and the control acts as a fixed droop converter.

Between time instants $12 \mathrm{~s}$ and 22s, the rectifier unit GSC3 increases the droop gain until the power reference achieved. At instant 22s, the system is working at a new equilibrium point with a fixed droop characteristic in the inverter side and a variable droop gain at the rectifier side. This means that the system could work without troubles or instabilities in this operation point. It can be observed that the reference of the disconnected GSC1 goes to the $E_{\min }$ threshold and the wind farm power reduction is not needed. After the time instant 40s, a new power references have been sent in order to maintain the power exchanged between areas constant. At time instant 70s a different power references have been sent.

\section{Conclusion}

A new control structure for M-HVDC grids has been presented. The presented scheme is composed by a primary, a secondary and a tertiary control similar to the traditional AC grid controls. The primary control is in charge of the DC voltage stability. The secondary control permits to achieve a given power setpoints, also after a contingency. The operational points of the proposed method, under normal and fault operation have been described. Some simulation scenarios, including a power converter disconnection, have been simulated in order to test the proposed system. The system stability under normal and fault conditions has been demonstrated using simulations.

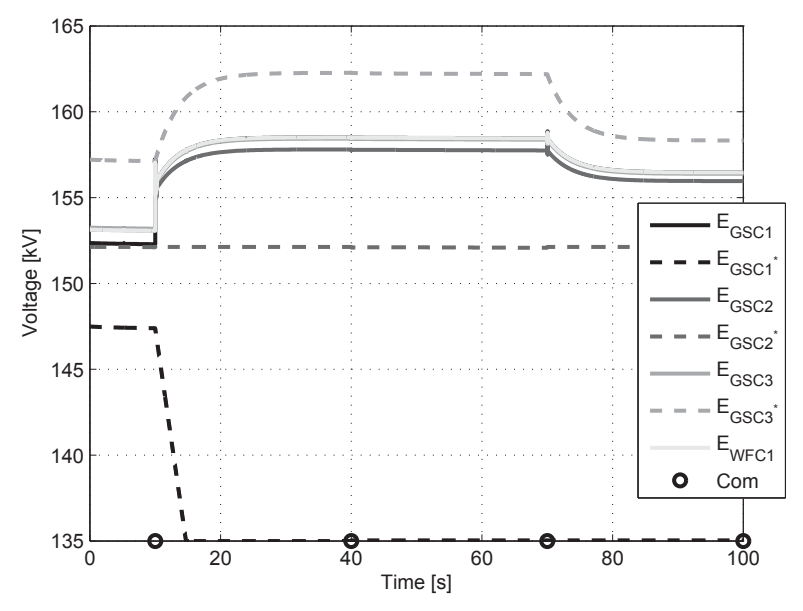

Figure 9: Voltage evolution during a reference change
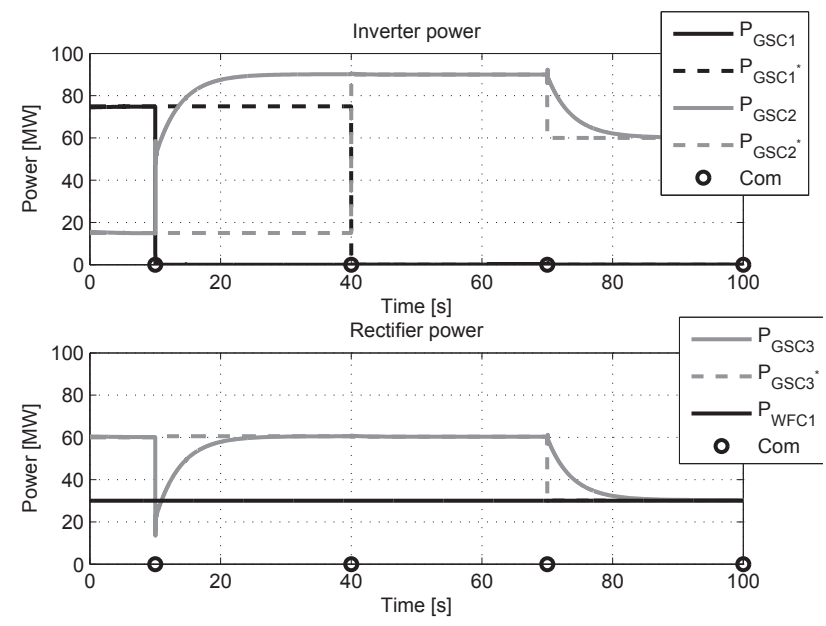

Figure 10: Power evolution during a reference change

\section{Acknowledgements}

This paper has been supported by the EIT KIC InnoEnergy project Smart Power. The work performed by Agusti Egea and Oriol Gomis is suppoted by the Ministerio de Ciencia e Innovación under the project ENE2009-08555. The work performed by Jef Beerten is supported by the Fund for Scientific Research (FWO) Flanders. Jef Beerten holds an "aspirant" mandate with the FWO.

\section{References}

[1] EWEA. (2012, Febrary) 2011 european statistics. EWEA. www.ewea.org.

[2] A. Bodin, "Hvdc light a preferable power transmission system for renewable energies," in Proceedings of the 2011 3rd International Youth Conference on Energetics (IYCE), July 2011, pp. $1-4$.

[3] B. Van Eeckhout, D. Van Hertem, M. Reza, K. Srivastava, and R. Belmans, "Economic comparison of VSC HVDC and HVAC as transmission system for a $300 \mathrm{MW}$ offshore 
wind farm," European Transactions on Electrical Power, vol. 20, no. 5, pp. 661-671, 2010.

[4] H. Ergun, D. Van Hertem, and R. Belmans, "Transmission system topology optimization for large-scale offshore wind integration," Sustainable Energy, IEEE Transactions on, vol. 3, no. 4, pp. 908 -917, oct. 2012.

[5] N. Ahmed, S. Norrga, H.-P. Nee, A. Haider, D. Van Hertem, L. Zhang, and L. Harnefors, "Hvdc supergrids with modular multilevel converters; the power transmission backbone of the future," in Systems, Signals and Devices (SSD), 2012 9th International Multi-Conference on, march 2012, pp. $1-7$.

[6] S. Gordon, "Supergrid to the rescue," Power Engineer, vol. 20, no. 5, pp. 30 -33, Oct.-Nov. 2006.

[7] F. Trieb, C. Schillings, T. Pregger, and M. O'Sullivan, "Solar electricity imports from the middle east and north africa to europe," Energy Policy, vol. 42, no. 0, pp. 341 353, 2012.

[8] A. Egea-Alvarez, A. Junyent-Ferré, and O. GomisBellmunt, "Active and reactive power control of grid connected distributed generation systems," in Modeling and Control of Sustainable Power Systems, ser. Green Energy and Technology, L. Wang, Ed. Springer Berlin Heidelberg, 2012, pp. 47-81.

[9] N. Flourentzou, V. Agelidis, and G. Demetriades, "Vscbased hvdc power transmission systems: An overview," Power Electronics, IEEE Transactions on, vol. 24, no. 3, pp. 592 -602, March 2009.

[10] M. Bahrman, J. Johansson, and B. Nilsson, "Voltage source converter transmission technologies: the right fit for the application," in Power Engineering Society General Meeting, 2003, IEEE, vol. 3, july 2003, p. 4 vol. 2666.

[11] D. Van Hertem and M. Ghandhari, "Multi-terminal VSC HVDC for the European supergrid: Obstacles," Renewable and Sustainable Energy Reviews, vol. 14, no. 9, pp. 31563163, 2010.

[12] J. Haefner and B. Jacobson, "Proactive Hybrid HVDC Breakers - A key innovation for reliable HVDC grids," in Cigré International Symposium. The electrical power system of the future. Integrating supergrids and microgrids. 13-15 September 2011 - Bologna (Italy), 2011, pp. 1-8.

[13] P. Bresesti, W. Kling, R. Hendriks, and R. Vailati, "HVDC connection of offshore wind farms to the transmission system," IEEE Transactions on Energy Conversion, vol. 22, no. 1, pp. 37 -43, March 2007.
[14] J. Beerten and R. Belmans, "Modeling and control of multiterminal vsc hvdc systems," Energy Procedia, vol. 24, no. 0, pp. 123 - 130, 2012.

[15] L. Xu, B. Williams, and L. Yao, "Multi-terminal dc transmission systems for connecting large offshore wind farms," in Power and Energy Society General Meeting - Conversion and Delivery of Electrical Energy in the 21st Century, 2008 IEEE, july 2008, pp. $1-7$.

[16] E. Prieto-Araujo, F. Bianchi, A. Junyent-Ferre, and O. Gomis-Bellmunt, "Methodology for droop control dynamic analysis of multiterminal vsc-hvdc grids for offshore wind farms," IEEE Transactions on Power Delivery, vol. 26, no. 4, pp. 2476 -2485, oct. 2011.

[17] F. D. Bianchi and O. Gomis-Bellmunt, "Droop control design for multi-terminal VSC-HVDC grids based on LMI optimization," in Proc. of the 50th Conference on Decision and Control, 2011, pp. 4823-4828.

[18] M. Aragues, A. Egea, O. Gomis, and A. Sumper, "Optimum voltage control for loss minimization in HVDC multi-terminal transmission systems for large offshore wind farms," Electric Power Systems Research, vol. Accepted for publication, 2012.

[19] L. Xu and L. Yao, "DC voltage control and power dispatch of a multi-terminal HVDC system for integrating large offshore wind farms," IET Renewable Power Generation, vol. 5, no. 3, pp. 223-233, 2011.

[20] N. Bengiamin and W. Chan, "Multilevel load-frequency control of interconnected power systems," Electrical Engineers, Proceedings of the Institution of, vol. 125, no. 6, pp. 521 -526, June 1978.

[21] A. Egea-Alvarez, A. Junyent-Ferre, O. Gomis-Bellmunt, J. Liang, J. Ekanayake, and N. Jenkins, "Operation and control of vsc-hvdc multiterminal grids for offshore wind," in Proceedings of the 2011-14th European Conference on Power Electronics and Applications (EPE 2011), 30 2011-sept. 1 2011, pp. 1 -9.

[22] J. Beerten, S. Cole, and R. Belmans, "Generalized steadystate vsc mtdc model for sequential ac/dc power flow algorithms," Power Systems, IEEE Transactions on, vol. 27, no. 2, pp. $821-829$, may 2012.

[23] J. Liang, O. Gomis-Bellmunt, J. Ekanayake, N. Jenkins, and W. An, International Journal of Electrical Power and Energy Systems, vol. 43, no. 1, pp. 54 - 62, 2012. 